East African Medical Journal Vol. 78 No. 7 July 2001

ATTITUDE AND SOCIAL CONSEQUENCES OF TUBERCULOSIS IN ADDIS ABABA. ETHIOPIA

M. Gelaw, MSc. T. Genebo. MPH, A. Dejene. MPH, E. Lemma. PhD and G. Eyob, MSc. Ethiopian Health and Nutrition Research Institute.

P.O. Box 5654/1242, Addis Ababa, Ethiopia.

Request for reprints to: Dr. M. Gelaw. Ethiopian Health and Nutrition Research Institute. P.O. Box 5654/1242. Addis Ababa, Ethiopia.

\title{
ATTITUDE AND SOCIAL CONSEQUENCES OF TUBERCULOSIS IN ADDIS ABABA, ETHIOPIA
}

\section{GELAW, T. GENEBO, A. DEJENE, E. LEMMA and G. EYOB}

\begin{abstract}
Objective: To gain a better understanding of the attitude and social consequences of tuberculosis (TB) in Addis Ababa, Ethiopia.

Design: A cross sectional survey using a structured questionnaire and a qualitative study based on the focus group discussion (FGD) technique.

Setting: Eight different kebeles (urban dwellers' associations) of six woredas (next higher administrative level to kebele).

Subjects and methods: Seven hundred and three participants, comprising 326 males and 377 females were interviewed using the written questionnaire and 36 recent and current TB patients through focus group discussion. Data were analysed using SPSS/PC statistical package. The proportions were compared using univariate and bivariate analyses to show the frequency distribution and evaluate the relationship among different variables. In FGD, topics relevant to the research questions were identified, sorted and analysed. Conclusions were then formulated.

Main outcome measures: Attitude of participants towards TB and its victims and social consequences of being a TB patient.

Results: Eighty three per cent of the respondents were aware that $\mathrm{TB}$ is a disease transmitted from one person to another and $80.1 \%$ perceived $\mathrm{TB}$ as an extremely severe disease. Of the total, $81.5 \%$ answered that $\mathrm{TB}$ is caused by cold, $69.0 \%$ feel that $\mathrm{TB}$ patients are not accepted in the community and $78.3 \%$ fear physical contact with TB patients. Most participants of the FGD sessions agreed that $\mathrm{TB}$ is a very dangerous, contagious but curable disease and the community has a generally negative attitude towards them. They also think that TB is associated with HIV/AIDS in the society. These attitudes have social consequences particularly the stigmatisation and social isolation of TB patients. Four hundred and four (57.5\%) respondents were found to be in favour of the short course chemotherapy against $226(32.1 \%)$ choosing the longer course. Clinical improvement and unavailability of some drugs or their cost were the first and second main reasons indicated, respectively, for defaulting by respondents. Conclusion: The perception by most respondents that tuberculosis is incurable, transmittable and associated with HIV/AIDS, led to the understanding that TB is a very dangerous disease. This, in turn, contributes to social avoidance and the resultant consequences in TB patients. Health education must be stepped-up within the TB control programme, and the psychosocial implications of TB should be given due attention.
\end{abstract}

\section{INTRODUCTION}

Ethiopia stands fourteenth in tuberculosis incidence in the world with an annual tuberculosis(TB) incidence of 90,000 and annual tuberculosis case rate of 155 per 100,000 of the population(1). It was estimated that there were only a total of 500,000 active tuberculosis cases in the country in 1968 (2), but 800,000 cases in 1978 (3) and that $3 \%$ of the general population was infected in 1980(4). Analysis of over three million outpatient visits in 1982 revealed that $62,029(2.0 \%)$ were for tuberculosis. Thus TB ranked fifteenth as a cause of outpatient visits nationwide and first as a cause of death in hospitals in the years 1987 and 1989(5).

When the community holds a strongly negative concept of tuberculosis, this can negatively influence the social relations and the moral identity of those afflicted by the disease and also efforts to control tuberculosis in general(6,7). Sensitive to such behavioural factors influencing tuberculosis control programme implementations, social science research on tuberculosis has been common in developing countries(6-9).

Research reports from developing countries indicate that $\mathrm{TB}$ is associated with 'stigma' in some cultural contexts $(6,7,10)$. In some communities, people thought that TB put a badmark on the family and was shameful. The majority of informants in some studies expressed concern when a TB patient visited their home. The terms pity and avoidance were also found to be associated with TB. It has been suggested that distribution of anti-TB 
drugs should be more secretive such that 'neighbours would not talk against people afflicted with TB'.

Little is known about the attitude of the community and the social consequences of TB in Ethiopia, as only a few reports are available(11-13). Information about factors contributing to the stigma is also lacking. Further, only a few studies have taken into account how the cost of antiTB drugs influences default following clinical improvement in Ethiopia. Reports indicate that one reason to shift to short-course chemotherapy in some developing countries was the low rate of compliance for the long 12 month course of standard therapy, especially where compliance with the longer course was found to be only $38-45 \%(6)$.

The objective of this study was to gain a better understanding of the perception. attitude and social consequences of tuberculosis in Addis Ababa, Ethiopia. Opinions about cost of anti-TB drugs in drug shops and attitude towards short course and standard long-term treatment regimens were also evaluated in relation to defaulting.

\section{MATEPIALS AND METHODS}

A community-based cross-sectional study, involving residents of the metropolis, was carried out during the months of June and July 1999. Socio-demographic characteristics were determined and information about potentially important determinant factors were recorded.

The study was both descriptive and analytical, exploring behavioral factors in relation to intended objectives.

The study population included individuals aged 15 years and above, residing in six randomly selected woredas (woredas $5,8,11,18,23$ and 27$)$. All zones of the city were included in the study.

A stratified random sample of kebeles (urban dwellers associations) from six woredas (next higher administratıve level to kebele) was selected. From each kebele (size ranging from 476 to 2500 households), 30 households were randomly selected and visited in June and July. 1999. Informed consent for the interview was obtained from each study subject. Ten random numbers per age category were tabulated by SAS PC for each selected kebele. Out of ten, the first, thidd, fifth, seventh and ninth subjects who consented were included in the study. When a study subject was not present, the enumerators made at least two or three attempts to contact the person. If the study subjects were absent upon repeated visits, an individual was replaced by the next randomlyselected informant. Following these procedures. 789 subjects were selected who consented to participate. Of these $703(326 \mathrm{M} /$ $377 \mathrm{~F})$ subjects completed the interview and the drop outs, either due to absence or refusal, were 86. For the purpose of analysis, the study subjects were stratified by ten-year age categories starting from age fifteen years.

The study methodology included interviewing the informants about perceptions and attitudes towards tuberculosis and its victims. Information on selected socio-demographic characteristics (sex, age, religion, occupation, educational status, etc.) was collected from participants by enumerators who were recruited from among the community members and who had completed 12-grade education. The investigators offered intensive training to the enumerators for a week prior to the survey on the content of the questionnaire and overall data collection skills. Closed-ended questions with multiple choices were used, with a last choice allowing the participant to suggest his/her opinion as required, if it was different from the choices listed for the question. Questions were presented in Amharic, the widely spoken language in the city and then translated and transcribed carefully into English by the investigators.

Actual questions presented were as follows (a language expert for both English and Amharic was consulted for correct translation). Do you know that TB is transmitted from person to person? If yes, how? (results presented in the text and Table 2a: Results).

Which one of the following (cold, bacteria. anger of gods, poison) is the cause for TB? A space to allow for suggestion of any other cause was provided. (Results presented in the text and Table 2c: Results). Do you fear TB? If yes why? ( choices are presented in the Table 2d: Results section. with a last space for a different opinion. Results are also found in Table 2d: Results). How do you classify TB as to its severity? (The choices and results obtained are presented in the text and Table $2 b$ : Results). Do you fear physical contacts (like shaking hands and hugging) with TB patients? (Yes/ No) (Results presented in the text and Table 3: Results).

Which one of the following llack of improvement on therapy. home far from clinic. clinical improvement. drug intolerance, cost and unavailability of drugs. length of treatment. work inconvenience. moved residence, and a last space for an opinion other than the reasons given) is the primary reason. from your experience or observation, for defaulting (discontinuation) of anti-TB treatment by TB patients? (results indicated in the text and Table 4: Results).

The translated version of the questionnaire with participants' responses was then coded and entered into a computer by a professional data encoder and a bio-statistician analysed the data.

Data were entered into the SPSS/PC statistical package. The proportion were compared using univariate and bivariate analysis to show the frequency distribution and evaluate the relationships among different variables. $\mathrm{P}<0.05$ was considered to he statistically significant.

To have a more complete picture of the situation, information was also collected from previous and current TB patients using a qualitative study based on the focus group discussion (FGD) technique. It is a method advocated increasingly in biomedical research(10). Focus groups are informal sessions in which participants are asked to discuss their perception of a specific topic. FGD especially has proved to be very useful in gathering information on sensitive topics $(14,15)$. The FGD method is sometimes preferred over collecting information using standardised questionnaires for it allows a more in-depth discussion of the topics, and it has the benefit of group synergy and facilitates the exploration of certain delicate topics without any interference from relatives and neighbours.

Focus group discussions were conducted with TB patients and subjects who had been sick but were cured from tuberculosis recently. Three male and three female groups were formed. Twenty four ( $13 \mathrm{M} / \mathrm{I} / \mathrm{F})$ of them were previous and $12(5 \mathrm{M} / 7 \mathrm{~F})$ current TB patients at the time of discussion. A FGD session lasted for one to two hours. Each focus group consisted of six subjects. All individuals included in the FGD participated voluntarily. Discussions in the focus groups were in Amharic. the widely spoken language in the capital, and then translated and transcribed into English for analysis. The average age of participants was 30 years ( \pm 15 years). Questions to elicit more specific and personal opinions and/or experiences with respect to social consequences were used by moderators during discussion 
sessions. The following research questions were presented to the FGD: How is TB perceived? Does the patient feel that he/ she is accepted by the family /society?

What are the social consequences of being a TB patient?

Topics relevant to the research questions were then identified, sorted and analysed by the investigators. Conclusions were then formulated.

\section{RESULTS}

Socio-demographic characteristics: Table 1 shows the socio-demographic characteristics of the study subjects of which $326(46.4 \%$ ) were males and $377(53.6 \%)$ females. The majority, that is, $605(86 \%)$ of them were Orthodox Christian. 334 ( 47.5\%) Amhara nationals, 189 (26.8\%) housewives, $251(35.7 \%)$ with secondary school level education, $350(49.8 \%)$ in the middle economic groups and $331(47.0 \%)$ single.

\section{Table 1}

Socio-demographic characteristics of the 703 subjects included in the study (Addis Ababa. Zomes: I. 2. 3. 4. 5. 6).

\begin{tabular}{|c|c|c|c|}
\hline Variable & Level & Frequency & $\%$ \\
\hline \multirow[t]{6}{*}{ Woreda } & 5 & 67 & 9.5 \\
\hline & 8 & 167 & 23.7 \\
\hline & 11 & 81 & 11.5 \\
\hline & 18 & 122 & 17.4 \\
\hline & 23 & 140 & 20.0 \\
\hline & 27 & 126 & 18.0 \\
\hline \multirow[t]{2}{*}{ Sex } & Males & 326 & 46.3 \\
\hline & Females & 377 & 53.6 \\
\hline \multirow[t]{4}{*}{ Age } & $15-19$ & 161 & 22.9 \\
\hline & $20-30$ & 245 & 34.8 \\
\hline & $31-45$ & 149 & 21.2 \\
\hline & $\geq 46$ & 148 & 21.0 \\
\hline \multirow[t]{3}{*}{ Religion } & Orthodox & 605 & 86.0 \\
\hline & Muslim & 66 & 9.3 \\
\hline & Other christians & 32 & 4.5 \\
\hline \multirow[t]{5}{*}{ Ethnicity } & Amhara & 334 & 47.5 \\
\hline & Oromo & 171 & 24.3 \\
\hline & Tigre & 38 & 5.4 \\
\hline & Gurage & 89 & 12.7 \\
\hline & Others & 71 & 10.0 \\
\hline \multirow[t]{7}{*}{ Occupation } & Gov. workers & 61 & 8.7 \\
\hline & Housewives & 189 & 26.8 \\
\hline & Private business people & 93 & 13.2 \\
\hline & Students & 1.54 & 21.9 \\
\hline & Unemployed & 1.37 & 19.5 \\
\hline & Pensioner & 42 & 6.0 \\
\hline & Others & 27 & 3.8 \\
\hline \multirow[t]{5}{*}{ Education } & Illiterate & 168 & 23.9 \\
\hline & Elementary & 155 & 22.0 \\
\hline & Junior & 96 & 13.6 \\
\hline & Secondary & 251 & 35.7 \\
\hline & Diploma and above & 33 & 4.7 \\
\hline \multirow[t]{3}{*}{ Living standard } & Lower & 209 & 29.7 \\
\hline & Middle & 350 & 49.8 \\
\hline & Upper & 144 & 20.5 \\
\hline \multirow[t]{3}{*}{ Marital status } & Single & 331 & 47.0 \\
\hline & Married & 258 & 36.6 \\
\hline & Others & 114 & 16.2 \\
\hline
\end{tabular}

Perception of tuberculosis: The majority, that is, $83.9 \%$ of the respondents have the knowledge that TB is a disease transmitted from one person to another (Table 2a), but many still do not know how. Many $(80.1 \%)$ also perceive TB as a disease which is extremely severe, and thus should be feared (Table $2 \mathrm{~b}$ ). About $81.5 \%$ answered that TB is caused by cold and $18.5 \%$ by other factors (bacteria, poison, anger of gods) combined (Table 2c).

Table 2

Participan's responses about mberculosis

\begin{tabular}{|c|c|c|}
\hline Variable & No. & $\%$ \\
\hline \multicolumn{3}{|l|}{ Knowledge that TB is transmittable ( $\mathrm{n}=703$ ) } \\
\hline Yes & 589 & 83.9 \\
\hline No & 106 & 15.0 \\
\hline Uncerain & 8 & 1.1 \\
\hline \multicolumn{3}{|l|}{ Perception as to the severity of TB $(n=703)$} \\
\hline Not severe & 9 & 1.3 \\
\hline Moderately severe & 8 & 11.5 \\
\hline Extremely severe & 563 & 80.1 \\
\hline Uncertain & 50 & 7.1 \\
\hline \multicolumn{3}{|l|}{ Factors indicated as the cause of TB $(n=703)$} \\
\hline Cold* & 573 & 81.5 \\
\hline Others (bacteria. anger of gods. poison, etc.) & 130 & 18.5 \\
\hline \multicolumn{3}{|l|}{ Reasons for fear of tuberculosis $(n=55 i)$} \\
\hline Association with HIV/AIDS & 293 & 53.2 \\
\hline Taken as incurable & 187 & 33.9 \\
\hline Others (Length of treatment. cost. etc.) & 71 & 12.9 \\
\hline
\end{tabular}

* $=$ exposure to change of temperature

Attitude towards the disease and TB patients: About $485(69.0 \%)$ informants feel that TB patients are not accepted in the community, and $551(78.3 \%)$ replied that they fear physical contacts with TB patients (Table 3 ). The latter showed statistically significant results when evaluated against sex, age, occupation, religion and marital status $(P$ $=0.03081, \mathrm{P}=0.00195, \mathrm{P}=0.00021, \mathrm{P}=0.00846$ and $\mathrm{P}$ $=0.00072$, respectively) (Table 3 ). Education, living standard, and ethnicity did not show significant relationships with fear of physical contact with TB patients ( $P>0.05$ ).

A significant positive relationship was found between knowledge of the transmissibility of TB and fear of physical contacts ( $P=0.03542)$, and similarly between the perception of TB as a very dangerous disease and fear of physical contacts $(P=0.04623)$.

Table $2 \mathrm{~d}$, shows that $293(53.2 \%)$ respondents fear TB through associating it with HIV, and hence the resultant avoidance by the community. About $34 \%$ of them however fear the disease thinking that it is incurable, and the remaining $12.9 \%$ attach it to the cost of medication and length of treatment as unbearable. 
Table 3

Fear of physical contuct with tuberculosis patients $(n=703)$.

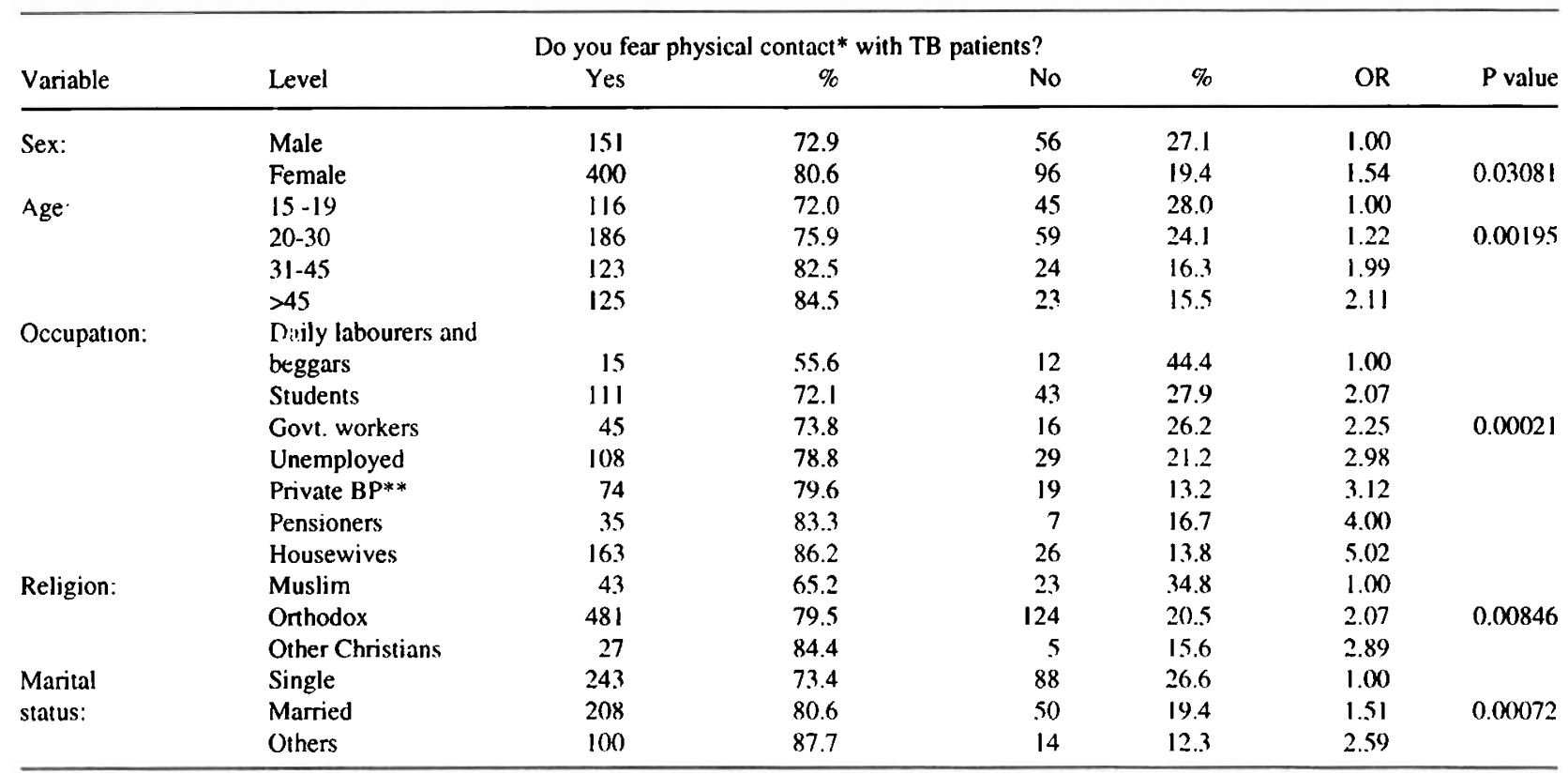

*hand shaking and hugging ** - private business people

Attitude towards treatment regimens: A choice was also given to informants between the short course (DOTsDirectly Observed Therapy short course) and the standard long course treatment for TB. Of the total respondents, $404(57.5 \%)$ were found to be in favour of the short course chemotherapy against $226(32.1 \%)$ choosing the longer course. Thirty eight $(5.4 \%)$ were not in favour of both the short and long course treatment regimens in this study and $35(5 \%)$ reserved to comment on either of the treatment courses. Five hundred and sixteen (73.4\%) respondents complained that the standard long course treatment is too long as a treatment course, among which $123(17.5 \%)$ still agreed that the longer course of treatment regimen is too long and hence difficult to complete.

Reasons for discontinuation (defaulting) of anti-TB treatment: All 703 interviewees were asked about their experiences regarding the probable reasons for discontinuation (defaulting) of anti-TB treatment by TB patients. As depicted in Table 4, clinical improvement

Table 4

Reasons for defaulting anti-tuberculosis drugs suggested by the 703 study subjects

\begin{tabular}{lrr}
\hline Reason & No. & $\%$ \\
\hline 1. Clinical improvement & 315 & 44.8 \\
2. Unavailability and cost of drugs & 149 & 21.3 \\
3. Length of treatment & 76 & 10.8 \\
4. Lack of improvement on therapy & 24 & 3.4 \\
5. Home far from clinic & 14 & 2.0 \\
6. Drug intolerance & 8 & 1.1 \\
7. Other social factors combined & 117 & 16.6 \\
\hline
\end{tabular}

(disappearance of disease symptoms), cost and unavailability of some drugs. length of treatment, lack of improvement on therapy, residential area far from the clinic, drug side-effects (intolerance), and finally other social factors in combination (missed appointment, work inconvenience. moved residence, childbirth, advised to stop medicine) were indicated by $315(44.8 \%), 149$ $(21.3 \%), 76(10.8 \%), 24(3.4 \%), 14(2 \%), 8(1.1 \%)$ and $117(16.6 \%)$ respondents, respectively, as factors responsible for discontinuation of anti-TB treatment by TB patients. FGD discussions with those experiencing TB revealed that cost of medications in private drug shops and pharmacies (after a government clinic had run out of anti -TB drugs), was the most repeatedly indicated factor responsible for defaulting or discontinuation of all or at least some of the anti-TB drugs recommended for treatment. This discussion revealed that incomplete drug therapy is common among many patients in the Capital as a result of the problem of drug supply.

Results from the FGD: How is TB perceived by the patient?: Focus group discussions revealed that TB patients perceive TB in a similar way to the community. Most participants of the FGD agreed that TB is contagious and is a very dangerous disease. Most of them however believe that it is curable. It was noted in these discussions that the presence of cured TB patients in the household, clinic or nearby village increased patients' hope that their disease could be cured, and thus improved their compliance with treatment. A female FGD participant, 15 years of age, said:

"I have my elder two sisters home cured from TB after proper treatment. I know TB is curable. 
Though I am not as good at taking medicines as they were, I will follow my treatment until it is finished".

Some participants, however, did not take TB as an infectious disease, but attributed it to a physical cause, particularly 'cold'. The participants spoke more about factors predisposing one to TB (such as poverty, too little food, overwork, expisure to wind, sleeping on cold floor, etc.) than the specific causative agent. Only some participants associated TB with germs or bacteria.

Does the patient feel that he/she is accepted by the society? Most FGD participants agreed that the community has a generally negative attitude towards them. They mentioned obvious avoidance starting from health professionals themselves just after the diagnosis of $\mathrm{TB}$ became known. A male participant aged 38, said: “...You can see their avoidance when they urge you to leave their laboratories and offices as soon as possible. when they become easily upset with you during further lab tests and drug delivery, and so on".

FGD participants further disclosed that they feel a similar rejection wherever their diagnosis is known: in their village, working place, market place, and the like. Sometimes, in social gatherings, they hear people talking about them from behind, even associating their disease with HIV/AIDS. Sisme of them said that, later, they resorted to telling people that their diagnosis was something else, but not TB. They feel that the society accepts TB as an incurable disease, and, as a result, rejects TB patients denying them contacts and even visits to households. A male participant aged 22 , said:

"One day, just after my diagnosis was known by the villagers, I was paying a visit to one of my friends home as usual. I remember. all family members were curious about my disease and asked me a lot of questions during my stay. I was too frank telling them everything about my disease. Then, when I left their home. I heard my friends' mother shouting behind my back at my friend not to invite me to their home any more. I am healthy today, but I still remember that incident"

Evident is also the fact that tuberculosis patients themselves feel that TB is associated with HIV/AIDS in the society. The FGD further revealed that the diagnosis of TB generally causes unhappiness among the patients' family members. However, once the diagnosis has been accepted, the family becomes very helpful for their sick family member. In general, it was males rather than female patients who spoke about the good support of family members.

What are the social consequences of being a TB patient?: Apart from avoidance of contact with TB patients and social isolation, most participants of the FGD agreed that $\mathrm{TB}$ can have strong influences on marriage life, and during engagement. One female FGD participant disclosed that her husband abandoned her after she was admitted for re-treatment after relapse. Others on the contrary, indicated that their spouses were very supportive. Another young lady mentioned that her diagnosis resulted in the breakdown of the relationship with her fiancee.

"....The case was that I was engaged to someone just before I was found to be a TB patient. The wedding day was already fixed. After diagnosis, he (the fiancee) complained that the disease is of not for my type (where living is relatively good) unless there is something else (he meant HIV/ AIDS). He then asked me to be tested for HIV. I was resentful, and the marriage was stopped".

FGD participants mentioned that this might be more of a problem for females than males, and would have more serious consequences in rural Ethiopia where the disease might be taken as hereditary.

\section{DISCUSSION}

It has been clearly shown in this study that TB is perceived as a very dangerous (extremely severe) and transmittable disease that should be feared by most people in the metropolis. This is also true for TB patients as the FGD sessions revealed. The perception of TB as a very dangerous disease might be ascribed to many factors. The relatively long time needed for its treatment. the high HIVassociated TB mortality observed (most dying AIDS patients show $\mathrm{TB}$ ) in the community today, the coughing up of blood associated with many afflicted by the disease, and the long standing comparison of TB with incurable tumours and cancer in the society (the Amharic name for TB, 'samba nekersa' translates as lung cancer or tumour) could be some of the factors responsible. The contribution of how illnesses are named to such perceptions of tuberculosis are also reported in other developing countries(16) indicating that, according to some people, weak lungs (a collective term used to denote several respiratory infece...ns mainly of ARI) develop TB which then transforms into cancer if not cured. The fact that $53.2 \%$ and $33.9 \%$ of those who fear tuberculosis was because they associate it with HIV/AIDS, and because they think it is incurable, respectively, supports this notion. Probably these are the two most important factors contributing to the fear, social isolation and resultant stigmatisation of those afflicted by the disease in the capital and other regions of the country.

The observation by the majority of respondents that TB patients are not well accepted in the society is further supported by the fact that more than three fourth (78.3\%) of respondents themselves fear any physical contact (hand shake, hugging, etc.) with those afflicted by the disease. Similar social rejection is also reported in a study conducted in rural parts of the country(11) and also in other developing countries(17). In the latter case, $76 \%$ of people in the survey stated that the way to prevent TB was to avoid contact with those ill with tuberculosis.

The fact that more females than males avoid contact with TB patients could be attributed to a relatively lower level of education and fewer social interactions outside of the home by females as compared to males in the society. 
This also explains why more housewives and pensioners than students and government workers reject physical contacts. Avoidance of physical contact with TB patients increases with age in our study. Younger ages reject physical contacts with TB patients less than the older age groups. This is perhaps due to a more interactive nature and easier life style resulting from limited life experience and a relatively better exposure to education by the younger age groups than the older age groups. This also applies to single individuals in our study who reject physical contacts less than the married, and divorced, widowed and separated subjects combined. Those who have experienced marriage are expected to have more life experiences resulting in more cautious behaviour and hence they avoid physical contacts with TB patients. They are also relatively older adults who have had less education than the young people.

Striking is the positive relationship found among the fear of physical contact with TB patients and knowledge of the transmissibility (without knowledge of the correct route of transmission) and perception as to the severity of tuberculosis. This clearly shows that incomplete understanding of the transmissibility of TB and a mere perception of TB as a very dangerous disease are among factors that contribute to the avoidance of TB patients by the community. This finding is further supported by the fact that the majority of study subjects, including FGD participants, did not even know the correct cause of TB. or were at least uncertain about it.

The perception by a significant percentage of respondents that $\mathrm{TB}$ is incurable, transmittable and totally associated with HIV/AIDS, led to the perception that TB is a very dangerous disease, and this, in turn, contributes to avoidance of $\mathrm{TB}$ natients and the resultant stigma (as will be discussed later) in patients afflicted by the discase.

Differences in physical rejection among different religious groups were also found in our study. This may be the result of differences in the conception or interpretation of the disease in the different religions. It may also arise from differences in the emphasis given to health education in the religious teachings of the different religions in the Capital.

The perception of TB as a curable disease by most participants of the FGD might be ascribed to the fact that some of the participants in the FGD were already cured subjects. From in-depth discussions, we understood that observation of cured patients in the household, nearby village and in the hospital or clinic, increased the hope of most patients that they could be cured. and improved their compliance. Patients had gained a better awareness about the disease from close relatives cured from $\mathrm{TB}$, and other patients encountered in the hospital and clinic while waiting for their turn. This emphasises the importance of TB clubs (13) in the fight against TB in Ethiopia wherever their feasibility is possible. It is assumed that this might be of great help to all other developing countries where health education is at a low level.

The major reason for discontinuing anti-TB drugs was clinical improvement shortly after the start of treatment.
This finding is comparable to those from other studies conducted in Ethiopia $(9,12)$. The second main reason being the unavailability (shortage) of all or some of the drugs among the range of anti-TB drugs recommended for treatment and the high cost of anti-TB drugs in private drug shops and pharmacies is reported for the first time and is very alarming in view of the fact that $\mathrm{TB}$ treatment is said to be free in the Capital. The fact that incomplete drug therapy is becoming a common practice by patients in the Capital is a serious problem as this is known to increase the risk of acquired bacterial resistance(18). Probably the major failure of the TB control program in the whole country arises from the poor supply and distribution of anti-TB drugs, and the poor organisational set-up of the program as a whole.

Preference for the short course (DOTs) chemotherapy by most informants and patients is highly encouraging. Several reasons can be mentioned. Short course therapy, which is directly observed. and administered, is an effective intervention for improving adherence of tuberculosis patients to treatment in a resource poor country like Ethiopia, provided that drugs are delivered effectively to the most peripheral level, and that health staff are adequately trained and regularly supervised. A cure rate up to $74.6 \%$ of patients and a sputum smear conversion up to $90 \%$ in smear-positive cases after two months of treatment is observed(19). Cost-wise, the six-month or other short course treatment regimens containing rifampicin and pyrazinamide in addition to isoniazid are found to be less expensive when compared to some of the standard twelvemonth regimens $(20)$.

Though the positive attitude and help in families for TB patients is encouraging, the feeling of paticnts that they are not accepted well by the society and the complete association of TB with HIV. could result in denial of diagnosis and rejection of treatment, which in turn would worsen the TB problem in the country. After all, health professionals are expected to be in the forefront to act as destigmatizers by educating people that there exist no major differences among diseases, including HIV/AIDS. All these diseases should not be feared. What is required is that those in contact with such illnesses need to be educated to handle the disease properly.

The social isolation and consequences of TB in our study corroborate the findings of other studies in Ethiopia and elsewhere $(6,10,11)$. Divorce rate due to tuberculosis was found to be $29.1 \%$ among TB patients in Estie, a rural part of Ethiopia. In addition, a loss or threat of losing jobs was reported ( 11 ). The latter was not indicated by our study participants in the FGD, and may need further work. Another study(19), on the other hand reported that, in Pakistan, even after a TB patient was successfully cured, the girl's or boy's prospects to marry remained diminished. Extrafamilial stigma for TB was also reported from the Philippines, where the vast majority of informants identified the terms pity and avoidance associated with $\mathrm{TB}(6)$. All these stigmas may lead patients to try to escape the social consequences of their disease by hiding the truth from 
those around them even to the extent of rejection of treatment.

In conclusion, we recommend that health education must be stepped-up to address the vulnerable groups within the TB control program, and the psycho-social implications of TB should be given due attention. The contribution of social stigma and unavailability of drugs free of charge to defaulting patients should not be overlooked. A need to introduce DOTs treatment and TB clubs wherever it is possible is advocated. Counselling some TB patients during the treatment period may also need to be integrated into the fight against tuberculosis.

\section{ACKNOWLEDGEMENTS}

We would like to thank she Ethiopian Health and Nutrition Research Institute (EHNRI) for its full financial and technical support of the project. We are also very grateful to the Health Bureau of Region 14 for approval of the study to be conducted in the Capital. Our special thanks goes to Mrs. Sue Edwards of the Department of Biology. Addis Ababa University, for her invaluable suggestions after reading the manuscript. Finally, we would like to thank all enumerators and study participants.

\section{REFERENCES}

1. World Health Organisation. Global tuberculosis control. WHO Report 1998. WHO/TB/98.237. Geneva. Switzerland: World Health Organisation, 1998.

2. Gordon C.G.I. A guide to tubercujosis in Ethiopia. MOH. Addis Ababa. 1968

3. Ministry of Health. Health services in socialist Ethiopia. $\mathrm{MOH}$. Addis Ababa. 1978.

4. Ministry of Health. Health manpower study. Ethiopia. $\mathrm{MOH}$, Addis Ababa. 1980.

5. Hodes R.M. and Azbite M. Tuberculosis. In the Ecology of health and disease in Ethiopia. eds. Kloos H.. and Zein Z.A.. Westview Press, USA, 1993. Pp 265 - 284.
6. Nichter $M$. Illness semantics and international health: The weak lungs/TB complex in the philippines. Soc. Sci. Med. 1994:38:649663 .

7. Shimao T. Drug resistance in tuberculosis control. Tubercle. 1987: 68 (suppl.): 5 - 1.5.

8. Wiese H,J.C. Tuberculosis in Rural Haiti. Soc. Sci. Med. 1974: 8:359- 362 .

9. Teklu B. Reasons for failure in treatment of pulmonary tuberculosis in Ethiopans. Tubercle. 1984: 65: 17-21.

10. Liefooghe R.. Michiels N.. Habib S.. Moran M.B. and De Muynck A. Perception and social consequences of tuberculosis: A focus group study of tuberculosis patients in Sailkot. Pakistan. Soc: Siri. Med. 1995; 41 :1685-1692.

11. Getahun H. Medical and social consequences of tuberculosis in rural Ethiopia. Abstract. Ethiop. Med. J. 1997: 35:207.

12. Demissie M. and Kebede D. Defaulting from tuberculosis treatment at the Addis Ababa tuberculosis center and factors associated with it. Ethiop. Med. J. 1994: 32: 97-106.

13. Getahun H. and Maher D. Contribution of 'TB Clubs' to tuberculosis control in a rural district in Ethiopia. Int. J. Tubere. Lumg. Dis. 2000: 4: $174-178$.

14. KiskerE.E. Teenagers talk about sex, pregnancy and contraception. Fam. Plamn. Perspect. 1985: 17:83.

15. Forrest K.A.. Austin D.M.. Valdes M.I.. Fuentes E.G. and Wilson S.R. Exploring norms and beliefs related to AIDS prevention among California Hispanic men. Fam. Plarm. Perspect. 1993: 25: 111

16. Alonzo F.. Desales R. and Diaz D. The concepts. attributes and beliefs of the Filipino on lung cancer. Phil. J. Int. Med. 1991: 29; 255-271

17. Ministry of Health of the Philippines. National health study of 1987. Department of Health. 1990.

18. Chaulet $P$. Compliance with anti-tuberculosis chemotherapy in developing countnes. Tubercle. 1987; 68 (suppl.):19-24.

19. Lienhardt C., Manneh K.. Bouchier V., Lahai G., Milligan P.J. and Mc Adam K.P. Factors determining the outcome of treatment of adult smear-positive tuberculosis cases in the Gambia. $\mathrm{mt} . J$ Tuberc, Luing. Dis. 1998: 2:712-718.

20. Grzybowski S. Cost in Tuberculosis control. Tuberde. 1987: 68(suppl.): 33-37. 